\title{
Twenty years' experience with myelomeningocele management at a single institution: lessons learned
}

\author{
Robert Kellogg, MD, ${ }^{1}$ Philip Lee, MD, ${ }^{2}$ Christopher P. Deibert, MD, ${ }^{3}$ Zachary Tempel, MD, ${ }^{4}$ \\ Nathan T. Zwagerman, MD, ${ }^{5}$ Christopher M. Bonfield, MD, ${ }^{6}$ Stephen Johnson, MD, ${ }^{2}$ and \\ Stephanie Greene, MD²
}

\begin{abstract}
${ }^{1}$ Advocate Children's Hospital, Park Ridge, Illinois; ' 2 Department of Neurosurgery, University of Pittsburgh Medical Center, Pittsburgh, Pennsylvania; ${ }^{3}$ Department of Neurosurgery, Emory University, Atlanta, Georgia; ${ }^{4}$ Mayfield Brain and Spine, Cincinnati, Ohio; ${ }^{5}$ Department of Neurosurgery, Medical College of Wisconsin, Milwaukee, Wisconsin; and ${ }^{6}$ Department of Neurosurgery, Vanderbilt University Medical Center, Nashville, Tennessee
\end{abstract}

OBJECTIVE The authors reviewed 20 years' experience with the surgical management of open myelomeningocele in a well-defined retrospective cohort from a single large academic medical center. Their goal was to define the characteristics of a modern cohort of children with myelomeningocele to allow for evidence-based decision-making for the treatment of these patients.

METHODS After IRB approval was obtained, the authors queried an operative database maintained by the Department of Neurological Surgery at Children's Hospital of Pittsburgh for patients who underwent closure of a myelomeningocele between 1995 and 2015. They identified 153 infants, and a retrospective chart review was performed.

RESULTS Eighty-eight percent of the patients required placement of a ventriculoperitoneal shunt, and $15 \%$ of these patients acquired shunt-related infections. Eighteen percent of patients underwent Chiari malformation type II (CM-II) decompression. Sixteen percent of patients underwent a tethered cord release. Three percent of patients died within the 1 st year of life. Predictors of an early demise included poor Apgar scores, large head circumference, and need for early $\mathrm{CM}-\mathrm{II}$ decompression. Functional motor outcome was slightly better than predicted by anatomical level of defect.

CONCLUSIONS Myelomeningoceles represent a severe birth defect with life-threatening complications. The authors provide long-term follow-up data and insight into factors that contribute to early death.

https://thejns.org/doi/abs/10.3171/2018.5.PEDS17584

KEYWORDS myelomeningocele; VP shunt; spina bifida; congenital

$\mathrm{S}$ PINA bifida affects approximately 3 out of 10,000 live births each year in the United States. ${ }^{4,12}$ The incidence is reported to be in decline due to a combination of improved maternal folic acid intake and elective termination. ${ }^{3,21}$ Myelomeningocele is the most common presentation of spina bifida and the most severe form of spina bifida that is compatible with long-term survival. While the mortality rate for these infants has been historically high, many children today are surviving into adulthood due to improved multidisciplinary management of the condition that afflicts them. ${ }^{6,17,20}$ There is a paucity of literature regarding patient characteristics that may predict poor outcomes and little long-term data. ${ }^{6,25}$

\section{Methods}

Over a period from 1995 through 2015, 164 infants who underwent closure of myelomeningocele defects following birth were identified through an operative database maintained by the neurosurgery department at Children's Hospital of Pittsburgh. A retrospective chart and radiological review was performed for all patients. Patients who had

ABBREVIATIONS CM-II = Chiari malformation type II; ETV = endoscopic third ventriculostomy; VPS = ventriculoperitoneal shunt.

SUBMITTED October 25, 2017. ACCEPTED May 10, 2018.

INCLUDE WHEN CITING Published online July 13, 2018; DOI: 10.3171/2018.5.PEDS17584. 
their initial myelomeningocele closure elsewhere $(n=4)$, those with meningoceles $(\mathrm{n}=3)$ or myelocystoceles $(\mathrm{n}=$ 1 ), and those lost to follow-up before the age of 2 years (n $=3$ ) were excluded, leaving 153 patients for analysis. All patients underwent standard neurosurgical closure within 24 hours of birth; our technique has been described elsewhere. ${ }^{16}$ Data collection points included Apgar scores, birth weight, anatomical level of defect (shown by radiograph, CT scan, or MR image), functional level of defect (lowest level of purposeful movement in either leg at the age of 24 months, as demonstrated by neurological examination), presence of shunt-treated hydrocephalus, symptomatic Chiari malformation type II (CM-II), and ambulatory ability. Patients were followed for a period ranging from 2 years to 20 years, with a mean of 9.9 years. Seventeen patients $(11 \%)$ were lost to follow-up after the age of 2 years during this period. These patients were excluded from further analysis.

Ventriculoperitoneal shunt (VPS) infection was defined as elevated CSF white blood cell count, positive CSF culture, or incision/skin breakdown involving shunt hardware at any point in time after shunt placement.

The anatomical level of defect was determined by identifying the lowest intact vertebral level on plain radiograph, CT scan, or MR image. The age of 24 months was chosen as the time to assess functional level for several reasons: It was believed to be the best time to evaluate neurological lower-extremity function-i.e., allowing for the resolution of in utero contractures and myelination of the corticospinal tracts, yet being at a stage before a child is likely to become symptomatic from a tethered spinal cord and prior to most orthopedic procedures; ${ }^{14,16}$ this age has been used in previous studies ${ }^{13,18}$ and standardization of methodology was thought to be important. Functional level was defined as the lowest level of purposeful lowerextremity movement at 24 months of age as determined by standard neurosurgical physical examination. This level was compared to the anatomical level for each patient. The difference between the anatomical and functional levels was calculated for each patient to define the expected and actual functional motor outcomes. All anatomical levels higher than L1 were defined as L1 for the purposes of this calculation.

CM-II decompressions were performed according to surgeon preference, and the details of the procedure in this cohort have been described elsewhere in the literature. ${ }^{15}$ Tethered cord release was similarly performed according to surgeon preference, and a manuscript detailing outcomes of this procedure at our institution is in preparation.

Pearson chi-square tests were used to compare groups for dependent variables consisting of categorical data. Logistic regression analysis was performed to examine the relationship between likelihood of shunt placement and anatomical level. Statistically significant differences were determined by $\mathrm{p}$ values $<0.05$ (2-tailed). All statistical analyses were performed using standard statistical software (IBM SPSS v22.0, IBM Corp.).

\section{Results}

The baseline characteristics of our cohort are listed in
TABLE 1. Characteristics of the pediatric patient cohort

\begin{tabular}{lc}
\hline \multicolumn{1}{c}{ Characteristic } & Mean (SD) \\
\hline Gestational age, wks & $37(2)$ \\
\hline Birth weight, $\mathrm{g}$ & $3072(638)$ \\
\hline Sex, \% female & 51 \\
\hline Apgar score & $7(2)$ \\
\hline 1 min & $8(1)$ \\
\hline 5 mins & $34.0(3.3)$ \\
\hline Initial head circumference, cm & $4.6(1.6)$ \\
\hline Largest diameter of defect, cm & $15(17)$ \\
\hline Length of stay, days & $19(64)$ \\
\hline Age at shunt placement, days & $1.4(1.9)$ \\
\hline No. of shunt revisions & 15 \\
\hline Shunt infection, \% & 18 \\
\hline CM-Il decompression, $\%$ & 16 \\
\hline Tethered cord release, $\%$ & 16 \\
\hline Seizure disorder, \% & 2 \\
\hline ETV only, no. of patients &
\end{tabular}

Values are reported as the mean (SD) unless otherwise indicated.

Table 1. On average, the patients were born at 37 weeks' gestation with a head circumference of $34 \mathrm{~cm}$, just above the 50th percentile for gestational age. In the majority of patients, the head circumference increased rapidly following myelomeningocele closure, such that the average patient required shunt placement at 19 days of age. Our surgical technique and complications of myelomeningocele closures, including wound infections and CSF leaks, have been published previously. ${ }^{16}$

\section{Shunting}

One hundred thirty-seven patients (90\%) were diagnosed with hydrocephalus. This diagnosis was defined as a rapidly increasing head circumference, head circumference crossing above the 95th percentile for gestational age, and progressive ventriculomegaly on serial ultrasound studies. These findings were often accompanied by splaying of sutures, bulging of the anterior fontanelle, or pseudomeningocele formation at the site of myelomeningocele repair, but these clinical findings in isolation were insufficient for a diagnosis of hydrocephalus.

One hundred thirty-five patients (88\%) underwent shunt placement (VPS or other type of shunt). Two patients with hydrocephalus were successfully treated with endoscopic third ventriculostomy (ETV) instead of shunting. The performance of an ETV instead of VPS surgery was based on physician preference and has not consistently been used at our institution in this patient population.

The mean age at shunt placement was 19 days, and the median age was 5 days. One patient had a shunt placed at 670 days, after being removed from a complex social situation and placed in foster care. The average patient had 1.4 shunt revisions (189 revisions/135 shunts placed), and the median number of revisions was 1 . The shunt revision rate per patient-year was 0.69 (137 shunts/2396 months of follow-up). Fourteen of 135 patients underwent VPS place- 
TABLE 2. Rate of shunt placement by anatomical level of the myelomeningocele defect

\begin{tabular}{ccc}
\hline Anatomical Level & Pts With Shunts/All Pts & $\%$ \\
\hline Thoracic & $9 / 9$ & 100 \\
\hline L1 & $11 / 11$ & 100 \\
\hline L2 & $9 / 11$ & 82 \\
\hline L3 & $29 / 30$ & 97 \\
\hline L4 & $32 / 35$ & 91 \\
\hline L5 & $35 / 39$ & 90 \\
\hline S1 & $9 / 16$ & 56 \\
\hline S2 & $1 / 2$ & 50 \\
\hline Overall no. & $135 / 153$ & 88 \\
\hline
\end{tabular}

Pts = patients.

ment at the time of myelomeningocele closure. There were 32 shunt infections in 20 patients followed over an average of 10 years; $15 \%$ of the 135 patients had shunt infections. Eight patients (40\%) had more than 1 shunt infection, with 5 patients having 2 infections each, 2 patients having 3 infections each, and 1 patient having 4 infections.

The anatomical level of defect is compared to need for VPS placement in Table 2. Three of the 5 patients who died were excluded from this calculation, as they did not undergo imaging that allowed verification of the anatomical level of the myelomeningocele defect prior to their demise. There was a significant association between a higher level of myelomeningocele defect and need for shunt placement $(\beta=0.59, \mathrm{p}=0.003$; OR $1.80,95 \% \mathrm{CI}$ 1.22-2.65). The mean anatomical-minus-functional-level calculation for our cohort is -0.3 (SD 1.4), meaning that the patients had slightly lower (better) neurological function than predicted by their anatomical levels. A more detailed analysis of this data has been published previously. ${ }^{10}$

\section{CM-II Decompression}

Twenty-eight patients (18\%) underwent CM-II decompression. All patients had previously undergone VPS placement. Shunts were evaluated for functionality prior to CM-II surgery and revised prior to CM-II decompression if needed. Only patients with shunts known to be functional underwent CM-II decompression. Our technique for CM-II decompression has been previously pub- lished..$^{15}$ Indications for CM-II decompression included the following: vocal cord paralysis on bronchoscopy $(\mathrm{n}=$ $10)$, stridor $(n=12)$, swallowing dysfunction $(n=21)$, aspiration pneumonia $(\mathrm{n}=13)$, aspiration on swallowing study $(n=12)$, central apnea $(n=12)$, opisthotonos $(n=3)$, head/ neck pain $(n=4)$, and syrinx formation $(n=21)$. No patient underwent CM-II decompression for a radiographic finding of syrinx alone, and many patients had multiple indications for surgery. Improvements were seen in these findings in approximately $50 \%$ of patients. The preoperative finding least likely to improve was the presence of a syrinx; only $19 \%$ had a postoperative decrease in syrinx size. Three patients (14\%) had an increase in the size of the syrinx, and in the remainder the syrinx was unchanged on postoperative imaging. Eight patients (29\%) required tracheostomy placement, and $2(25 \%)$ were ventilator dependent until their deaths in infancy. Eleven patients (34\%) required gastrostomy tube placement. Three patients died in a delayed fashion at the ages of 6 years, 8 years, and 12 years, respectively; 1 developed progressive brainstem compression despite multiple decompressive surgeries, including an odontoidectomy. The other 2 patients, who were tracheostomy and ventilator dependent, died of respiratory complications. The mortality rate for patients who underwent CM-II decompression was $16 \%$ in the 1 st year of life, and it was $25 \%$ over the long term. Fifty percent of those undergoing tracheostomy placement after CM-II decompression died before reaching adulthood.

\section{Tethered Cord}

Twenty-four patients (16\%) underwent tethered cord releases. Thirty-five percent of those undergoing CM-II decompressions also underwent tethered cord releases. Indications included back or leg pain, progressive scoliosis, an enlarging distal syrinx, change in bladder function, and motor decline. Patients did not undergo surgery for a syrinx in the absence of symptoms.

\section{Mortalities}

Five patients $(3 \%)$ died in the 1st year of life (Tables 3 and 4). These patients had lower Apgar scores at 1 and 5 minutes. Each patient who died in the 1st year of life had respiratory difficulties apparent at birth and severe hydrocephalus warranting shunt placement at the time of myelomeningocele closure. The head circumference of the

TABLE 3. Perinatal deaths

\begin{tabular}{|c|c|c|c|c|c|c|}
\hline $\begin{array}{l}\text { Pt } \\
\text { No. }\end{array}$ & $\begin{array}{l}\text { Age at } \\
\text { Death } \\
\text { (days) }\end{array}$ & Respiratory Issues & $\begin{array}{c}\text { Age at } \\
\text { Shunt } \\
\text { Placement }\end{array}$ & $\begin{array}{c}\text { CM-II } \\
\text { Decompression }\end{array}$ & Other Issues & Cause of Death \\
\hline 1 & 7 & No respiratory effort & 1 day & No & Quadriparesis & Support withdrawn \\
\hline 2 & 9 & No respiratory effort & 1 day & No & Enterobacter sepsis, abdominal compartment syndrome & Failed resuscitation \\
\hline 3 & 11 & $\begin{array}{l}\text { Stridor, vocal cord } \\
\text { paralysis }\end{array}$ & 1 day & Yes & & Support withdrawn \\
\hline 4 & 64 & Apneic spells $20-35$ mins & 1 day & Yes & Swallowing dysfunction & Support withdrawn \\
\hline 5 & 296 & Central apnea & 1 day & Yes & $\begin{array}{l}\text { Swallowing dysfunction, volvulus at } 199 \text { days, short } \\
\text { bowel syndrome, liver disease }\end{array}$ & Support withdrawn \\
\hline
\end{tabular}


TABLE 4. Perinatal deaths versus long-term survivors

\begin{tabular}{lccc}
\hline \multicolumn{1}{c}{ Factor } & $\begin{array}{c}\text { Deaths } \\
(\mathrm{n}=5)\end{array}$ & $\begin{array}{c}\text { Long-Term } \\
\text { Survivors }\end{array}$ & $\begin{array}{c}\mathrm{p} \\
\text { Value }\end{array}$ \\
\hline Gestational age, wks & 35.6 & 37.4 & 0.08 \\
\hline Birth weight, g & 3054 & 3072 & 0.90 \\
\hline Sex, \% female & 60 & 49 & 0.42 \\
\hline Apgar score & & & \\
\hline$\quad 1$ min & 4 & 7 & 0.001 \\
\hline 5 mins & 8 & 9 & 0.05 \\
\hline Initial head circumference, $\mathrm{cm}$ & 43.1 & 33.8 & 0.001 \\
\hline
\end{tabular}

patients who died was on average $10 \mathrm{~cm}$ larger than that of the long-term survivors. Three of these patients underwent CM-II decompression in the first 6 weeks of life. Of those not undergoing CM-II decompression, one had support withdrawn at the request of the family at 7 days of age, and the other was critically ill prior to death at 9 days of age. No CM-II decompression in this group produced improvement in respiratory or swallowing dysfunction.

\section{Discussion}

Myelomeningocele, representing the most common form of spina bifida, is a complex disorder requiring multiple neurosurgical procedures to optimize patient outcomes. The percentage of patients requiring permanent CSF diversion in our cohort was comparable to that of other published studies. ${ }^{6}$ Authors of a recent publication have postulated that a lower rate of shunting is possible with more stringent operative criteria; ${ }^{5}$ it remains to be seen whether avoidance of shunt placement produces comparable neurological outcomes. The incidence of shunt infections in our cohort is likely higher than average due to the long follow-up. Our institutional shunt infection rate was $5.7 \%$ in 2016 according to Hydrocephalus Clinical Research Network criteria. ${ }^{11}$ There may also be a higher incidence of shunt infection in this patient population due to skin breakdown in neonates and patients with paralysis, the need for multiple surgeries, and bacteremia from urinary tract infections. This topic will be a focus of future work from our group.

Twenty-eight patients in our study underwent CM-II decompression. The indications for this procedure were similar to those in other published studies, as was the percentage of patients who improved neurologically following surgery. ${ }^{1,19}$ While this procedure was historically considered to be controversial, more recent data have supported early and aggressive decompression. ${ }^{22,23}$ Interestingly, the preoperative finding that was least likely to improve in this series is syringomyelia, whereas other groups have found this to respond well to decompression. ${ }^{19}$ This may be in part due to the relatively small numbers of patients described in the literature. It may also be due to the inclusion of shunt revisions as treatment for CM-II symptoms in some series, as well as the inclusion in our series of MR images acquired many years following a CM-II decompression. ${ }^{19}$

Families have many questions related to the diagnosis of spina bifida. Among the most common, in our experience, are questions related to functional motor outcome and survival. Functional motor outcome has long been closely associated with the anatomical level of the defect. ${ }^{8}$ Retrospective studies conducted in the 1990s indicated that the functional motor outcome is slightly higher (worse) than would be predicted by anatomical level.,9,11,12 Our results indicated that functional outcome is slightly better than predicted based on the anatomical level of the defect, independent of the mode of delivery. ${ }^{10}$ This finding may overestimate our patients' ultimate functional motor outcome due to the fact that our analysis was done when patients were 2 years of age. Motor deficits may become more apparent or worsen as patients age. Notably, a motor decline associated with the need for tethered cord release in this patient population is well established, ${ }^{2,718}$ This outcome may also be related to our more modern cohort of patients. Data regarding the long-term functional outcome of this patient cohort is beyond the scope of the study and will be investigated in future work. ${ }^{10}$

The literature is clear that long-term survival should be expected given modern medical and surgical management of this disease. ${ }^{6}$ At the same time, practitioners experienced with treating patients with myelomeningoceles know that this condition is fraught with life-threatening complications. Recent studies have attempted to identify factors associated with early mortality, including size of the defect, head circumference, and time to defect closure. ${ }^{24}$ Efforts have previously been made to identify these early prognostic factors during pregnancy. ${ }^{27}$ In 1972, John Lorber controversially described a set of criteria that should prompt clinicians to withhold treatment for myelomeningoceles after birth. ${ }^{13}$ These included a thoracolumbar defect, severe paraplegia, gross enlargement of the head ( $2 \mathrm{~cm}$ above the 90th percentile), severe kyphosis, and other severe congenital defects or birth injuries. While great strides in surgical technique and management of infection have been made since his study was published (with its $37.5 \%$ mortality rate in the 1st year of life), our study supports the contention that massive hydrocephalus is a poor prognostic sign. Our study additionally identifies central respiratory abnormalities (apnea or stridor) that become apparent shortly after birth as an ominous finding. Several studies have previously identified brainstem dysfunction in association with a CM-II as the main cause of early death in myelomeningocele patients. ${ }^{6,26}$ As in the current case series, others have reported a percentage of patients whose brainstem dysfunction does not improve following CM-II decompression. ${ }^{23,28}$ It can be concluded that, while death is uncommon in the perinatal period, it can be predicted by the presence of stridor or apnea immediately after birth, a large head circumference, and poor Apgar scores. Families should be counseled about this possible outcome, which occurred in $3 \%$ of our patients.

\section{Conclusions}

Spina bifida has largely become a chronic condition that can be effectively managed by a multidisciplinary team of clinicians. However, a large head circumference, low Apgar scores, and symptomatic CM-II at birth por- 
tend a dismal prognosis. Clinicians should elucidate these characteristics promptly following birth to better counsel families regarding their child's condition and potential outcome.

\section{References}

1. Akbari SHA, Limbrick DD Jr, Kim DH, Narayan P, Leonard JR, Smyth MD, et al: Surgical management of symptomatic Chiari II malformation in infants and children. Childs Nerv Syst 29:1143-1154, 2013

2. Al-Holou WN, Muraszko KM, Garton HJ, Buchman SR, Maher CO: The outcome of tethered cord release in secondary and multiple repeat tethered cord syndrome. J Neurosurg Pediatr 4:28-36, 2009

3. Atta CAM, Fiest KM, Frolkis AD, Jette N, Pringsheim T, St Germaine-Smith C, et al: Global birth prevalence of spina bifida by folic acid fortification status: a systematic review and meta-analysis. Am J Public Health 106:e24-e34, 2016

4. Boulet SL, Yang Q, Mai C, Kirby RS, Collins JS, Robbins $\mathrm{JM}$, et al: Trends in the postfortification prevalence of spina bifida and anencephaly in the United States. Birth Defects Res A Clin Mol Teratol 82:527-532, 2008

5. Bowman RM, Boshnjaku V, McLone DG: The changing incidence of myelomeningocele and its impact on pediatric neurosurgery: a review from the Children's Memorial Hospital. Childs Nerv Syst 25:801-806, 2009

6. Bowman RM, McLone DG, Grant JA, Tomita T, Ito JA: Spina bifida outcome: a 25-year prospective. Pediatr Neurosurg 34:114-120, 2001

7. Bowman RM, Mohan A, Ito J, Seibly JM, McLone DG: Tethered cord release: a long-term study in 114 patients. J Neurosurg Pediatr 3:181-187, 2009

8. Cochrane DD, Wilson RD, Steinbok P, Farquharson DF, Irwin B, Irvine B, et al: Prenatal spinal evaluation and functional outcome of patients born with myelomeningocele: information for improved prenatal counselling and outcome prediction. Fetal Diagn Ther 11:159-168, 1996

9. Coniglio SJ, Anderson SM, Ferguson JE II: Functional motor outcome in children with myelomeningocele: correlation with anatomic level on prenatal ultrasound. Dev Med Child Neurol 38:675-680, 1996

10. Greene S, Lee PS, Deibert CP, Tempel ZJ, Zwagerman NT, Florio K, et al: The impact of mode of delivery on infant neurologic outcomes in myelomeningocele. Am J Obstet Gynecol 215:495.e1-495.e11, 2016

11. Kestle JRW, Riva-Cambrin J, Wellons JC III, Kulkarni AV, Whitehead WE, Walker ML, et al: A standardized protocol to reduce cerebrospinal fluid shunt infection: the Hydrocephalus Clinical Research Network Quality Improvement Initiative. J Neurosurg Pediatr 8:22-29, 2011

12. Kshettry VR, Kelly ML, Rosenbaum BP, Seicean A, Hwang L, Weil RJ: Myelomeningocele: surgical trends and predictors of outcome in the United States, 1988-2010. J Neurosurg Pediatr 13:666-678, 2014

13. Lorber J: Spina bifida cystica. Results of treatment of 270 consecutive cases with criteria for selection for the future. Arch Dis Child 47:854-873, 1972

14. Luthy DA, Wardinsky T, Shurtleff DB, Hollenbach KA, Hickok DE, Nyberg DA, et al: Cesarean section before the onset of labor and subsequent motor function in infants with meningomyelocele diagnosed antenatally. N Engl J Med 324:662-666, 1991

15. McDowell MM, Blatt JE, Deibert CP, Zwagerman NT, Tempel ZJ, Greene S: Predictors of mortality in children with myelomeningocele and symptomatic Chiari type II malformation. J Neurosurg Pediatr 21:587-596, 2018
16. McDowell MM, Lee PS, Foster KA, Greene S: The use of external ventricular drainage to reduce the frequency of wound complications in myelomeningocele closure. Pediatr Neurosurg 53:100-107, 2018

17. McLone DG: Treatment of myelomeningocele: arguments against selection. Clin Neurosurg 33:359-370, 1986

18. Mehta VA, Bettegowda C, Amin A, El-Gassim M, Jallo G, Ahn ES: Impact of tethered cord release on symptoms of Chiari II malformation in children born with a myelomeningocele. Childs Nerv Syst 27:975-978, 2011

19. Messing-Jünger M, Röhrig A: Primary and secondary management of the Chiari II malformation in children with myelomeningocele. Childs Nerv Syst 29:1553-1562, 2013

20. Oakeshott P, Hunt GM: Long-term outcome in open spina bifida. Br J Gen Pract 53:632-636, 2003

21. Parker SE, Mai CT, Canfield MA, Rickard R, Wang Y, Meyer RE, et al: Updated National Birth Prevalence estimates for selected birth defects in the United States, 2004-2006. Birth Defects Res A Clin Mol Teratol 88:1008-1016, 2010

22. Pollack IF, Kinnunen D, Albright AL: The effect of early craniocervical decompression on functional outcome in neonates and young infants with myelodysplasia and symptomatic Chiari II malformations: results from a prospective series. Neurosurgery 38:703-710, 1996

23. Pollack IF, Pang D, Albright AL, Krieger D: Outcome following hindbrain decompression of symptomatic Chiari malformations in children previously treated with myelomeningocele closure and shunts. J Neurosurg 77:881-888, 1992

24. Rodrigues ABD, Krebs VLJ, Matushita H, de Carvalho WB: Short-term prognostic factors in myelomeningocele patients. Childs Nerv Syst 32:675-680, 2016

25. Steinbok P, Irvine B, Cochrane DD, Irwin BJ: Long-term outcome and complications of children born with meningomyelocele. Childs Nerv Syst 8:92-96, 1992

26. Stevenson KL: Chiari Type II malformation: past, present, and future. Neurosurg Focus 16(2):E5, 2004

27. Thompson DNP: Postnatal management and outcome for neural tube defects including spina bifida and encephalocoeles. Prenat Diagn 29:412-419, 2009

28. Vandertop WP, Asai A, Hoffman HJ, Drake JM, Humphreys RP, Rutka JT, et al: Surgical decompression for symptomatic Chiari II malformation in neonates with myelomeningocele. J Neurosurg 77:541-544, 1992

\section{Disclosures}

The authors report no conflict of interest concerning the materials or methods used in this study or the findings specified in this paper.

\section{Author Contributions}

Conception and design: Kellogg, Greene. Acquisition of data: Deibert, Tempel, Zwagerman, Bonfield, Johnson. Analysis and interpretation of data: Kellogg, Deibert, Greene. Drafting the article: Kellogg. Critically revising the article: Kellogg, Greene. Reviewed submitted version of manuscript: Kellogg, Greene. Approved the final version of the manuscript on behalf of all authors: Kellogg. Statistical analysis: Lee. Administrative/techni$\mathrm{cal} /$ material support: Greene. Study supervision: Greene.

\section{Correspondence}

Robert Kellogg: Advocate Children's Hospital, Park Ridge, IL. robert.kellogg@advocatehealth.com. 